\title{
Da estética romântica à arte do estilo: conexões do jovem Nietzsche com August Koberstein
}

\author{
Anna Hartmann Cavalcanti*
}

Resumo: O objetivo deste artigo é investigar o lugar cada vez mais destacado que a questão da forma de expressão passa a ocupar nos escritos de Nietzsche no período entre o fim dos estudos escolares e os primeiros anos dos estudos universitários. Pretendo elucidar a análise desenvolvida por Koberstein, em sua obra Compêndio de história da literatura nacional alemã, sobre a questão da forma de expressão no movimento romântico, para em seguida mostrar como o crescente interesse de Nietzsche pelo emprego de recursos expressivos nos antigos poemas desdobra-se, no período universitário, na busca de uma arte estilística entendida como elo entre arte e ciência.

Palavras-chave: Nietzsche, Koberstein, estilo, literatura, filosofia, estética romântica.

* Universidade Federal do Estado do Rio de Janeiro (UNIRIO), Rio de Janeiro, RJ, Brasil.

ORCID https://orcid.org/0000-0001-6929-8966

Correio eletrônico: anna.hart.cav@gmail.com.br 


\section{Introdução}

Na célebre escola Pforta, Nietzsche foi aluno de um dos mais conceituados historiadores da escola romântica, August Koberstein, que nela lecionou por mais de 50 anos e dedicou-se durante todo esse período a uma detalhada pesquisa sobre a história da literatura alemã. Em 1827, publicou sobre o tema o livro Grundriss zur Geschichte der deutschen Nationalliteratur, que aqui traduzimos por Compêndio de história da literatura nacional alemã. ${ }^{1} \mathrm{O}$ livro, voltado especificamente para professores e alunos dos cursos ginasiais, foi sendo continuamente ampliado e enriquecido até formar, em 1866, uma obra em três volumes que tratava a história da literatura alemã dos tempos mais antigos até o início do século XIX. O fato de seu livro, que era também material de referência de seus cursos de alemão em Pforta, ter sido elaborado ao longo de décadas de atividade docente, permite estabelecer uma estreita ligação entre as aulas e o conteúdo que compõe a obra. Nietzsche, por sua vez, ingressou em Pforta em 1858 e concluiu seus estudos em 1864, o que indica que o período de sua formação coincide com a época em que Koberstein, já na quarta edição da obra, reunia material para o último volume publicado em $1866 .^{2}$

São inúmeros os documentos que indicam o uso do Grundriss nas aulas, dos relatórios anuais de Pforta até relatos de antigos alunos. ${ }^{3}$

\footnotetext{
1 Koberstein, A. Grundriss zur Geschichte der deutschen Nationalliteratur, la edição,1827; 2ª edição, 1830; $3^{\text {a }}$ edição revisada e ampliada, 1837; $4^{\text {a }}$ edição revisada e ampliada, volume 1,1847 ; volume 2, 1856; volume 3, 1866. Para as citações, cuja tradução é de minha autoria, será indicado o ano da edição seguido do número da página.

2 Cf. CAVALCANTI, 2019.

3 Vale mencionar, a esse respeito, o relato de Wilamowitz-Möllendorff que, em suas memórias sobre Pforta, observou que as aulas de Koberstein eram compostas da leitura de longas passagens de seu livro sobre a história da literatura. Erich Schmidt, também aluno de Koberstein, fez o seguinte relato das aulas de história da literatura: "Com formação enciclopédica, memória surpreendente e entusiasmo pelos heróis da poesia, conhecia bem o alemão arcaico e era um professor imponente, um pesquisador bem-sucedido e incansável, que dominava como poucos a literatura alemã moderna". Apud Heyer, 1943, p. 137-138.
}

148 | Cad. Nietzsche, Guarulhos/Porto Seguro, v.42, n.2, p. 147-174, maio/agosto, 2021. 
Da estética romântica à arte do estilo: conexões do jovem Nietzsche...

Já o exame dos relatórios escolares, no período de 1827 a 1847, correspondente ao surgimento das quatro edições da obra, mostra como as ementas dos cursos de alemão de Koberstein acompanham o aprofundamento de seu estudo. Durante o período de 1827, ano em que surgiu a primeira edição da obra, até 1837, ano do surgimento de sua terceira edição, era explicitado na ementa que o curso de alemão de Koberstein consistia na exposição da história da literatura segundo o Grundriss. Após a publicação da terceira e da quarta edição, respectivamente em 1837 e 1847, nas quais o estudo é progressivamente ampliado e enriquecido com novos resultados de pesquisa, desaparece da ementa qualquer referência à obra do autor, ao mesmo tempo em que o conteúdo da ementa passa a estar dividido em duas unidades, uma especificamente dedicada à história antiga da literatura e a outra dedicada à história moderna. No período de estudos de Nietzsche em Pforta, a ementa da primeira série permaneceu dividida em duas unidades, cada ano dedicado a um período da história da literatura. Assim, se o aprofundamento da obra se reflete claramente na mudança das ementas ao longo dos anos, a própria obra se torna um indicativo do conteúdo do curso de Koberstein.

Ao longo das reedições do Grundriss, observa-se a referência cada vez mais clara de Koberstein ao papel do movimento romântico na formação da literatura alemã. Na segunda edição, de 1830, Koberstein apresenta um panorama do intenso diálogo entre criação artística e reflexão estética, que abre novos caminhos na literatura do final do século XVIII, destacando o papel dos jovens românticos na articulação entre essas duas perspectivas. Essa abordagem é aprofundada na quarta edição, de 1856, a partir de um estudo das novas teorias do belo e seus efeitos sobre as filosofias de Fichte, Schelling e dos jovens românticos, cuja atividade é descrita ora como poesia, ora como crítica, ora como tradução, indicando o surgimento de novas formas de conexão entre arte e filosofia. Até que, em 1866, no último 
volume, essa investigação se desdobra em diversos capítulos sobre os pensadores românticos, figurando entre os aspectos tratados o lugar que a forma de expressão passa a ocupar na reflexão filosófica. Koberstein aborda o interesse da escola romântica por um modo de escrita que vai além das fronteiras entre poesia e prosa, ciência e arte, culminando em uma reflexão sobre a forma de expressão que envolve também a atividade crítica e filosófica.

O período em que Nietzsche estuda em Pforta, de 1858 a 1864, coincide com a época de redação do último volume do Grundriss, como vimos, o que torna altamente provável que o detalhamento da obra tenha primeiramente se expressado nas aulas. Além disso, os trabalhos e anotações escolares do jovem expressam uma significativa afinidade com o curso de literatura. ${ }^{4}$ De outubro de 1862 a outubro de 1864, na última série do ginásio, Nietzsche cursa a disciplina de Koberstein sobre a história da literatura alemã, estudando na chamada primeira série inferior, a história da literatura antiga e, na primeira superior, a história da literatura moderna. ${ }^{5} \mathrm{Um}$ dos temas da primeira inferior eram as antigas sagas germânicas e sua relação com a canção popular na Idade Média, especialmente a elucidação de passagens da Canção dos Nibelungos. Nietzsche ocupa-se intensamente com a literatura antiga nesse período, elaborando sobre o tema trabalhos escolares, mas também poemas, dramas e composições musicais que nascem de sua própria iniciativa. Em outubro de 1862, redige o trabalho "Descrição do caráter de Kriemhild segundo os Nibelungos" (KGWI/3, p. 38-43), para o curso de alemão, no qual aborda as figuras trágicas do antigo mito germânico, elaborando uma análise do caráter das personagens. Nesse período, dedica-se à leitura das Lições sobre belas letras e arte e do ensaio Bürger, nos quais A.W.

4. Sobre o contato de Nietzsche com Koberstein no período escolar cf. Figl, 2003, p. 87-92.

5 Em Pforta, o tempo integral de formação era de seis anos, estando o ensino organizado em três séries ginasiais, as chamadas terceira, segunda e primeira, cada uma subdividida em inferior e superior. $\mathrm{O}$ aluno iniciava seus estudos na terceira série inferior, avançava para a terceira superior e permanecia em cada série um ano. Cf Heumann, 1994, p. 121-5. Cf. também Bohley, 1976, p. 298-300.

150 | Cad. Nietzsche, Guarulhos/Porto Seguro, v.42, n.2, p. 147-174, maio/agosto, 2021. 
Da estética romântica à arte do estilo: conexões do jovem Nietzsche...

Schlegel ${ }^{6}$ oferece uma viva exposição dos principais aspectos da primeira estética romântica. ${ }^{7}$ No ano seguinte, de maio a agosto, renovam-se indícios de seu interesse pela literatura, tais como a leitura da História da Literatura, de Hettner, e também a de Bernhardy, um conjunto de anotações a respeito do ensaio de Emerson sobre o belo e o esboço de um estudo comparativo entre a poesia épica grega e germânica. ${ }^{8}$ No horizonte dessas leituras, Nietzsche volta a se ocupar com a Canção dos Nibelungos, mas de uma nova perspectiva, pois o que agora o interessa não é mais o caráter das personagens, mas "o ponto de vista estético", ${ }^{9}$ o exame da particularidade da forma de expressão na poesia.

É possível estabelecer pontos de contato significativos entre a pesquisa de Koberstein, na qual se destaca a questão da crítica e da escrita poético-filosófica do primeiro romantismo alemão, e o crescente interesse do jovem Nietzsche, no último ano escolar, pelo ponto de vista estético, que se traduz em indagações sobre o uso da alegoria nos antigos poemas, sobre os recursos poéticos de representação do belo, colocando em primeiro plano a questão da forma de expressão. Esse campo de interesses é retomado nos anos seguintes, quando, já na Universidade de Leipzig, Nietzsche redige seu primeiro artigo acadêmico e se vê confrontado com a questão de seu próprio estilo, contrapondo em uma série de cartas a forma seca dos tratados filológicos com a perspectiva de criar para si uma

60 excerto foi elaborado, segundo os editores das obras completas, no período de outubro de 1862 a março de 1863 (KGW I, 2, p. VI). Cf. também CAVALCANTI, 2017.

7 No volume de 1866, em suas longas notas de rodapé, Koberstein (p.2329-2331) recomenda vivamente a leitura de ambos os textos. Considera o ensaio Bürger "o mais feliz exemplo da estética romântica, de sua direção positiva", destacando esse artigo entre os escritos que melhor expõe as concepções da escola romântica.

8 Cf, a respeito, H. G. Hödl, 2000, p. 70.

9 Cf. Nietzsche, Friedrich. Historisch-kritische Gesamtausgabe. org. por H.J.Mette/K.Schlechta. Vol. 2, München: 1994, p. 221. Para as próximas citações, BAW II, seguida do número da página. No presente artigo, as traduções das citações de Nietzsche e dos demais autores, salvo indicação, são de minha autoria.

Cad. Nietzsche, Guarulhos/Porto Seguro, v.42, n.2, p. 147-174, maio/agosto, 2021.| 151 
"arte estilística" (KSB 2.214). O objetivo deste artigo é investigar o lugar cada vez mais destacado que a questão da forma de expressão passa a ocupar nos escritos de Nietzsche no período entre o fim dos estudos escolares e os primeiros anos dos estudos universitários. Pretendo, em primeiro lugar, examinar o modo como Koberstein analisa o movimento romântico, especialmente no que diz respeito à questão da forma de expressão, para em seguida mostrar como o crescente interesse do jovem Nietzsche pelo emprego de recursos expressivos nos antigos poemas desdobra-se, posteriormente, na busca de uma arte do estilo entendida como elo entre arte e ciência.

\section{Koberstein}

Na segunda edição de seu Grundriss, publicada em 1830, Koberstein traça um panorama da história da literatura do século XVIII, articulando os novos campos de conhecimento que surgiam à época com as transformações que ocorriam na criação poética e literária. No amplo quadro que daí resulta, a filologia clássica é descrita, entre as ciências, como a mais próxima da arte. Se Winckelmann inaugura uma visão inteiramente nova da arte antiga, F. A. Wolf redimensiona a investigação do texto literário a partir do método histórico-crítico, consolidando em novas bases a ciência da antiguidade. Ao longo desse período cresce o interesse pela literatura de antigas culturas, desenvolve-se pouco a pouco uma renovação dos estudos da Idade Média, o que abre caminho, sobretudo com os irmãos Grimm, para a formação de uma ciência da antiguidade alemã. Herder, a partir de seu estudo da poesia de diferentes povos e épocas, ilumina com sua investigação as fontes das quais nasceram as mais antigas poesias, contribuindo para esclarecer os elos que ligam a arte antiga e moderna. Esse fecundo diálogo entre passado e presente, como assinala Koberstein (1830, p. 262-263), encontra eco no movimento poético da década de setenta que buscava, a partir do estudo dos antigos gregos, sobretudo dos cantos homéricos, 
Da estética romântica à arte do estilo: conexões do jovem Nietzsche...

criar uma autêntica poesia popular, imprimindo à arte um caráter nacional: "esse movimento, no qual se destaca Bürger e suas criações no gênero lírico, contribui, ao lado das primeiras grandes poesias de Goethe, para despertar o sentido de uma autêntica poesia popular, fundando uma nova época da literatura alemã".

No âmbito da filosofia, começara já a se desenvolver uma doutrina da arte com a estética de Baumgarten, ao passo que, nas últimas décadas do século, a crítica de Kant produz efeitos decisivos não apenas na vida científica, mas também artística e literária. $\mathrm{O}$ impacto da filosofia crítica sobre o conjunto da vida literária alemã e, particularmente, sobre a crítica estética manifestou-se com maior intensidade a partir de 1795, com a divulgação da nova doutrina e a publicação de comentários sobre o tema especialmente por Reinhold e Fichte. Também Schiller dedicou-se ao estudo da filosofia crítica, daí resultando uma importante reflexão sobre a arte, ao mesmo tempo em que sua criação poética alcançava o período mais brilhante. No mesmo período despontam na cena filosófico-literária alguns jovens poetas e críticos, A.W. Schlegel, Friedrich Schlegel, Novalis e Tieck, que contribuem para a renovação da crítica estética, conduzindo-a a um fundamento filosófico mais profundo. Koberstein (1830, p. 223) mostra como "os anos noventa", nos quais não apenas Goethe e Schiller consolidam sua amizade, mas também os jovens que irão formar a escola romântica, "são marcados por um contato entre produção literária e reflexão estética que irá imprimir uma direção singular à literatura alemã".

Os jovens que despontam na cena filosófico-literária, chamados por seus opositores de "românticos", desenvolvem atividades em múltiplos campos, entrecruzando filosofia, poesia, crítica e tradução. Um importante aspecto da atividade crítica dos irmãos Schlegel era a articulação entre a história da arte e a produção literária da época, destacando-se, entre as temáticas por eles abordadas, a valorização da criação poética da Idade Média alemã, assim como 
da obra de Shakespeare, a elucidação do papel de Lessing e Goethe na formação da literatura nacional, a análise da poesia romântica em sua relação com o antigo e o clássico. Além de sua atividade crítica e histórico-literária, os irmãos Schlegel atuaram no campo da poesia e da tradução, tendo Friedrich se destacado "por sua criação poética e literária", enquanto August pelas "primorosas traduções de Shakespeare e da poesia dramática dos espanhóis" (Koberstein,1830, p. 300). Novalis publica seus fragmentos sobre filosofia, literatura e estética, além de se destacar por sua produção no campo da literatura e da poesia, ao passo que Tieck concentra seus ideais românticos e seu talento crítico especialmente na criação poética. Descrevendo os diferentes campos de atuação de cada um dos membros do grupo, Koberstein (1830, p. 301) ressalta que a "reflexão que daí resultou, devido a sua riqueza e força crítica, abriu caminho para o que de melhor foi produzido pela literatura alemã nos anos noventa".

Assim, na edição de 1830, correspondente ao período inicial de sua pesquisa, Koberstein esboça em linhas gerais o diálogo que, impulsionado pela filosofia de Kant, se estabelece entre a criação artística e a reflexão estética. Na última edição de sua obra, no volume de 1856, como veremos a seguir, ele irá aprofundar essa abordagem, mostrando como o diálogo entre os dois campos contribuiu de modo significativo para o surgimento de uma filosofia da arte.

No volume de 1856, Koberstein (p. 864-866) introduz novas perspectivas para elucidar o movimento crítico que alcança o seu auge, no fim do século XVIII, com a filosofia de Kant: se já na década de setenta tornavam-se visíveis as ressonâncias da reflexão sobre os antigos na criação poética, com a crítica de Kant "novos caminhos se abrem não apenas na filosofia, mas na vida espiritual como um todo e entre seus escritos e a literatura não cessam de surgir pontos de contato". Fichte e Schelling tomam parte nos debates em torno da filosofia crítica, também Schiller, como vimos, produz uma fecunda reflexão sobre a doutrina kantiana do belo e seus elos com 
Da estética romântica à arte do estilo: conexões do jovem Nietzsche...

a literatura poética. Logo em seguida, os românticos, especialmente os irmãos Schlegel, inspirados na reflexão desenvolvida por Fichte e Schelling, propõem pensar de nova perspectiva as conexões entre arte e ciência, poesia e filosofia. Mas para a consolidação de uma "autêntica filosofia da arte" (1856, p.1791), nas palavras de Koberstein, foi particularmente decisivo o esforço no sentido de uma fundamentação mais profunda do conceito de belo. Tal esforço foi iniciado, antes mesmo da terceira crítica, por Karl Philipp Moritz em seu escrito intitulado Sobre a imitação formadora do belo (Über die bildende Nachahmung des Schönen), publicado em $1788 .^{10}$

Koberstein afirma, em uma longa nota, que o mais brilhante conceito de beleza produzido nos anos anteriores à publicação da Crítica do Juízo (1790) está contido no escrito de Moritz, acima mencionado, em cuja concepção Goethe tomou parte. ${ }^{11}$ Nesse escrito, Moritz parte do princípio dominante na estética da época, de que a imitação da natureza seria o princípio constitutivo da arte, mas nele introduz uma mudança significativa: o artista não deve imitar os produtos da natureza, mas a natureza como princípio produtor, procurando formar e criar como ela. A reformulação da noção de imitação, que na doutrina estética clássica significava tomar a natureza como um modelo situado fora do artista, implica não apenas a concepção de que o artista cria e forma autonomamente, mas que a atividade criadora repete no plano individual o processo mais amplo da natureza, "desdobrando-se organicamente, como

10 Enquanto a reflexão sobre a arte de Moritz é analisada com riqueza de detalhes por Koberstein (1856, pp. 1791-93), como veremos mais adiante, o mesmo não ocorre com a terceira crítica de Kant, abordada de forma mais genérica, sobretudo no sentido de expor o seu impacto no pensamento da época. Se na primeira crítica, como assinala Koberstein, Kant lança uma questão em direção aos fundamentos do conhecimento, na terceira ele inaugura uma nova forma de apreender a natureza do belo, associada a uma nova concepção da imaginação, ao mesmo tempo em que estabelece, muito claramente, a diferenciação entre o domínio da arte e os domínios moral, utilitário e científico. Com isso a filosofia de Kant demarca, de modo decisivo, a especificidade do domínio estético.

11 Koberstein (1856, p.1791) refere-se à estada de Goethe em Roma, em 1786, durante a qual manteve estreito contato com Moritz. Segundo relato de Goethe, teria sido durante as longas conversas que tiveram nesse período que o escrito teria surgido.

Cad. Nietzsche, Guarulhos/Porto Seguro, v.42, n.2, p. 147-174, maio/agosto, 2021. | 155 
um pequeno mundo, no todo maior da natureza" (Koberstein, 1856, p.1791-2). O poeta cria, como a natureza, tendo em vista o todo, engendrando cada parte em relação à disposição de conjunto. Isso significa que a criação artística é pensada como uma relação de determinação mútua entre a parte e o todo, na qual o grande todo da natureza espelha-se em cada coisa individual, assim como cada coisa experimenta sua relação recíproca com o todo. Mas nessa relação há que se considerar, como observa Koberstein, que a natureza em sua totalidade, o verdadeiro "todo que subsiste por si mesmo", ultrapassa a medida de nossa intuição e que, portanto, nossa imaginação só pode conceber, a cada vez, um todo singular que se assemelha a um pequeno mundo. A atividade artística consiste em transpor para um todo finito, uma espécie de microcosmo, as infinitas associações existentes no grande todo da natureza. Se a arte não pode abarcar a natureza em sua totalidade, ela procura expor o infinito de forma concentrada, na qual "cada todo belo concebido pelo artista é a impressão, em miniatura, do supremo belo no todo maior da natureza" (Koberstein,1856, p. 1793).

A teoria de Moritz, que desenvolve o princípio de autonomia da arte, da obra como um todo que possui o valor e a finalidade de sua existência em si própria, despertou o vivo interesse de Schiller, tendo desempenhado também um papel importante nas doutrinas da arte dos irmãos Schlegel e de Schelling. ${ }^{12}$ A reflexão desenvolvida nesse período sobre a arte poética, assim como as novas perspectivas que orientam a teoria do belo, produzem efeitos significativos na literatura da época. Assim, se na década de setenta o estudo sobre os cantos homéricos ecoa na criação poética, contribuindo na formação de uma poesia popular, na década de oitenta o escrito sobre o belo de Moritz instiga a reflexão de Goethe, que dele participa de algum

12 No que diz respeito à filosofia contemporânea, Todorov dedicou uma atenção especial à exposição da estética de Moritz e de seus efeitos nos círculos literários e filosóficos da época. Cf. Todorov, T. Teorias do símbolo. Campinas: Papirus, 1996, pp. 194-211.

156 | Cad. Nietzsche, Guarulhos/Porto Seguro, v.42, n.2, p. 147-174, maio/agosto, 2021. 
Da estética romântica à arte do estilo: conexões do jovem Nietzsche...

modo, enquanto a Crítica do Juízo de Kant impulsiona as investigações de Schiller, que, inspirado pela terceira crítica, produz uma fecunda reflexão. Os efeitos das novas teorias do belo, aliadas à filosofia crítica, se propagam em círculos cada vez mais amplos, impulsionando a reflexão de Fichte e Schelling, aos quais se ligam cada vez mais estreitamente os jovens pensadores da escola romântica. O campo de interesse dos jovens românticos, por sua vez, é de tal maneira descrito que o laço formado entre a reflexão sobre a arte e a criação artística parece se fundir em algo inteiramente outro, uma atividade que se manifesta ora como poesia, ora como crítica, ora como tradução, convertendo em objeto de pensamento as próprias fronteiras entre arte e ciência, poesia e filosofia.

Ao longo das reedições do Grundriss, nas quais Koberstein amplia e aprofunda sua obra, evidencia-se cada vez mais o papel do movimento romântico na formação da literatura alemã. ${ }^{13} \mathrm{O}$ último volume, de 1866, contém diversos capítulos sobre os pensadores românticos, com detalhados comentários sobre a teoria e a crítica por eles desenvolvidas, nos quais se evidencia como traço característico o lugar que a forma de expressão passa a ocupar na reflexão filosófica. Se até aqui, como vimos, Koberstein destacou o papel do diálogo entre literatura e filosofia na formação de uma filosofia da arte, com a escola romântica são postas em questão justamente as fronteiras entre filosofia, literatura e arte, o que equivale, como veremos a seguir, a repensar a questão da forma de expressão na atividade crítica e filosófica.

O estreitamento dos vínculos entre os jovens fundadores da escola romântica, o amadurecimento dos fins teóricos e práticos que buscavam como grupo só se consolidam com a criação da revista Athenäum. Um dos objetivos da revista, que foi desde o

13 Koberstein disponibiliza listas detalhadas dos artigos publicados pelos pensadores românticos em diversas revistas da época. Tal lista, acompanhada de comentários, era inserida nas notas de rodapé e oferecia um panorama geral da obra de cada autor ou das produções relativas à determinada temática ou período. 
Cavalcanti, A. H.

início organizada pelos irmãos Schlegel, era apresentar escritos, especialmente no campo da arte e da filosofia, sob uma livre forma:

Enquanto o estilo alternava tratados com cartas, conversações, breves observações e fragmentos, o conteúdo alternava juízos particulares com investigações gerais, teoria com exposição histórica, visões de diferentes aspectos do povo alemão da época com visões do estrangeiro e do passado, especialmente da Antiguidade clássica (Koberstein,1866, p. 2237).

Além das regulares contribuições dos irmãos Schlegel, editores da revista, o primeiro volume continha contribuições de Novalis e de Schleiermacher, assim como de Caroline Schlegel. ${ }^{14}$ Com a fundação da revista, que contou em seus últimos volumes com a contribuição de novos participantes, tais como A. L. Hülsen, aluno de Fichte em Iena, assim como A. F. Bernhardi e Dorothea Veit, a escola romântica adquire um órgão autônomo de divulgação de sua produção no campo da poesia, da crítica estética e da ciência. Detalhando cada vez mais sua análise da primeira fase da escola romântica, Koberstein inclui longos comentários sobre a produção filosófica-literária de cada um dos membros do grupo, sua vida comunitária em Iena, da qual participou também Schelling, que se torna próximo dos irmãos Schlegel nesse período. ${ }^{15}$ No que diz respeito a Tieck, que editava à época o seu próprio jornal poético, Koberstein (1866, p. 2239-40)

14 Vale mencionar, a esse respeito, o comentário de Ernst Behler de que os irmãos Schlegel pretendiam que a revista fosse uma "obra comum", na qual atuassem não apenas como editores, mas também como autores e que nela "nem a forma nem o conteúdo seriam claramente definidos". Assim, diferenciandose das revistas de crítica literária da época, orientadas para a história e a filologia, o Athenäum tornou-se o porta-voz dos princípios estéticos do primeiro romantismo, entre os quais se destaca não mais a oposição, mas sim a indissolúvel união entre discurso crítico e criação literária. Cf. BEHLER, E. Le premier romantisme allemand. Trad. E. Décultot e C. Helmreich. Paris: PUF, 1992, p. 207-8.

15 Koberstein (1866, p. 2256) transcreve o relato de August Schlegel sobre o tempo em que viveu junto a seus amigos em Iena: "A reflexão sempre renovada sobre primorosas obras do espírito era nossa ocupação predileta, nossa maior alegria descobrir escritos do gênio desconhecidos ou que haviam caído no esquecimento. Mesmo a franca discordância de opiniões agia sobre cada um de nós como um estímulo; a maior parte do que depois realizamos ou não realizamos foi esboçada naquela época - Minhas recordações buscam ainda muitas vezes com saudade aquela livre e fecunda comunidade do espírito (...)".

158 | Cad. Nietzsche, Guarulhos/Porto Seguro, v.42, n.2, p. 147-174, maio/agosto, 2021. 
Da estética romântica à arte do estilo: conexões do jovem Nietzsche...

faz uma detalhada exposição sobre sua vida e obra, sua tradução de Dom Quixote e sua crítica à artificialidade da poesia do final do século XVIII, ao princípio do naturalismo estético que se manifestava como uma "recusa do invisível".

Enquanto Schiller e Goethe produziram efeito nas tendências literárias da época sobretudo como poetas, o impacto maior da atividade dos autores românticos se deu no domínio da crítica estética. Koberstein (1866, p. 2289) assinala que a força produtiva da crítica se desenvolveu "tanto em uma direção negativa, como polêmica contra as tendências medíocres da literatura e contra o princípio dominante do naturalismo na arte, quanto em uma direção positiva, como valorização do que havia de exemplar e significativo na literatura". Em suas Lições sobre literatura, arte e espírito da época, de 1803, August Schlegel contrasta "os princípios em vigor na escola de poesia, que se convertiam em rígidos modelos a serem seguidos, com a nova geração de poetas que surge na década de setenta e passa a se relacionar de forma inteiramente diferente com seus modelos" (Koberstein,1866, p. 2316). De um lado, ele mostra como pode ser fecunda uma intuição poética nascida de uma época estranha a nossa, como por exemplo as inovações produzidas pelo poeta Bürger que, inspirado pelos cantos homéricos e pela mais antiga poesia inglesa, rompe com as regras de escola e imprime um autêntico sentido popular à poesia alemã. De outro, destaca a obra de Goethe que incorpora de forma original em sua poesia o exemplo dos antigos e se torna um modelo para as novas gerações, mas um modelo entendido em um sentido diferente, já que os jovens "seguem a via aberta por ele sem imitá-lo, nela prosseguindo com autonomia e ampliando-a" (Koberstein,1866, p. 2325).

Assim, a direção positiva da crítica romântica pressupõe um tipo ativo de imitação, que amplia e recria com autonomia seu modelo, o que implica, como enfatiza Koberstein, a visão orgânica do nascimento de uma obra de arte, de sua unidade e 
indivisibilidade, a parte concebida do ponto de vista do todo. August Schlegel observa que existe na poesia "espírito e letra", uma "parte criadora e uma parte realizadora", o interior em concordância com o exterior, interpenetrando-se mutuamente (Apud Koberstein, 1866, p. 2324). O poeta não imita, como vimos anteriormente, um modelo situado fora dele, mas imita a natureza como ela cria, a atividade criadora desdobrando-se organicamente, como um "pequeno mundo", no todo maior da natureza. No horizonte de tal concepção se desenvolveu a direção positiva da crítica estética romântica, sintetizada por Koberstein em quatro princípios: compreender cada obra organicamente, apreendendo o sentido do todo que o artista conserva no mais íntimo de sua criação; considerar a estreita conexão da obra com sua época, apreendê-la em seus laços históricos; conceber filosoficamente a obra como parte "do grande organismo de todas as artes e ciências", construindo-a geneticamente em relação a esse organismo. Apreender um tal organismo supõe, segundo Friedrich Schlegel, conhecer não apenas a obra de um autor, mas também as obras com as quais esta obra se relaciona, mesmo de modo pouco evidente, "com as quais ela forma um todo, das quais ela própria não constitui senão um membro" (Apud Koberstein,1866, p. 2328).

O trabalho crítico é, enfim, orientado pelo princípio, aqui elucidado por Friedrich Schlegel, de que a poesia só pode ser criticada pela poesia: "um juízo artístico que não seja ele próprio, quer na matéria, quer através de uma bela forma, uma obra de arte não possui direito de cidadania no reino da arte" (Apud Koberstein, 1866, p. 2329). De acordo com esse princípio, que embaralha as fronteiras entre crítica e arte, o discurso sobre a poesia só pode se dar através de uma linguagem ela mesma poética. August Schlegel, no ensaio sobre Hermann e Dorothea de Goethe, considerado por Koberstein (1866, p. 2333) "um verdadeiro modelo de crítica estética", aproxima o ritmo do discurso narrativo à métrica da poesia e à cadência oratória, indicando por meio de tais semelhanças o caráter poético da escrita em prosa. 
Da estética romântica à arte do estilo: conexões do jovem Nietzsche...

Por outro lado, a partir da noção de "poesia transcendental", exposta por Friedrich Schlegel, a poesia constitui-se ao mesmo tempo como poesia e "poesia da poesia", a reflexão sobre si própria, a atividade reflexiva torna-se elemento poético essencial. A tarefa da crítica é, dessa perspectiva, expor não apenas como matéria, mas como forma o elemento reflexivo da obra. ${ }^{16}$ Bernhardi, citado nessa passagem por Koberstein (1866, 2329), esclarece esse princípio a partir de um comentário sobre a criação poética: "o artista produz segundo um conjunto harmônico de sensações uma intuição harmônica e completa, sendo capaz de despertar, por meio dessa última, o primeiro em toda sua pureza". Assim, na pureza ou, dito em outros termos, na "unidade da sensação", reside o ponto de união entre o crítico e o artista. $\mathrm{O}$ crítico procura expor a unidade da sensação suscitada pela arte de uma forma ela mesma artística, as impressões líricas expostas liricamente, a poesia exposta poeticamente.

No horizonte dessas indagações, August Schlegel descreve a filosofia de seu tempo como uma "nova filosofia", em cuja forma se expressa "uma consciência intensificada, um grau de reflexão sobre si própria como jamais havia se manifestado nos empreendimentos filosóficos". ${ }^{17}$ Assim como a filosofia, que se volta reflexivamente sobre si própria, tornando-se crítica, também "o poeta deve, pelo estudo da poesia antiga e moderna, não apenas ampliar sua compreensão das obras do passado, mas intensificar a clareza sobre a essência de sua arte", o que significa, curiosamente, que ele deve, "em certo grau", se tornar "filósofo, físico e historiador" (Apud Koberstein, 1966, p.2325). O poeta que toma a poesia em consideração do ponto de vista de sua história, amplia a compreensão da obra e se

16 Ernst Behler mostrou, no âmbito de estudos contemporâneos, como essa perspectiva foi de importância primordial para a estética romântica, constituindo-se como seu núcleo reflexivo: o questionamento da oposição entre poesia e prosa, da separação entre literatura e filosofia. BEHLER, op.cit, 1996, pp.210-221.

17 Trata-se de uma passagem da quarta lição da Vorlesungen über Literatur, Kust und Geist der Zeitalter (Lições sobre literatura, arte e espírito da época) transcrita por Koberstein, 1866, p.2324-25. 
converte, em certo grau, em historiador, ao passo que ao se voltar reflexivamente sobre a criação poética converte-se em filósofo. Se, de acordo com Friedrich Schlegel, a linguagem pela qual o crítico expõe o seu juízo deve ser ela própria artística, August Schlegel evidencia aqui o outro lado da crítica romântica, aquele do poeta cuja obra de arte deve ser ela própria, em certo grau, histórica e filosófica. Assim, os pensadores românticos, ampliando o próprio conceito de crítica, começam a revirar as fronteiras entre a filosofia e a arte, daí resultando uma indagação acerca da linguagem e da forma de expressão que se dirige também à crítica e à escrita filosófica.

Koberstein constrói, em seu compêndio da história da literatura, através de um vasto conjunto de citações e de referências, um vivo cenário do final do século XVIII, no qual a reflexão crítica, levada a novos patamares com a filosofia de Kant, se articula a novos campos de conhecimento que se formam no âmbito da arte, da história e da antiguidade clássica em fecundo diálogo com a literatura. Se de um lado o autor do Grundriss analisa as ressonâncias do crescente contato entre literatura e filosofia na formação de uma filosofia da arte, de outro ele esclarece, pela riqueza de citações e de referências, como a escola romântica introduz novas perspectivas nesse diálogo, das quais resulta uma reflexão sobre a forma de expressão que articula a atividade poética e filosófica. Talvez não seja de outra maneira que se deva compreender a significativa observação de Koberstein, na introdução ao seu compêndio, sobre os critérios que orientaram a escolha de obras de prosa científica a serem tratadas:

a história da prosa científica só será abordada nos casos daquelas obras que, além de seu conteúdo especializado (...), se elevaram de algum modo à beleza e se destacaram pela singularidade da forma ou que tiveram influência decisiva sobre o desenvolvimento da poesia (1847, p.2).

A compreensão das transformações da literatura alemã, no final do século XVIII, requer a análise não apenas de obras de crítica 
Da estética romântica à arte do estilo: conexões do jovem Nietzsche...

estética ou de filosofia que se destacaram por seu conteúdo, mas também pela beleza ou singularidade da forma, o que implica, como vimos, os deslocamentos de um movimento reflexivo que começa a problematizar as fronteiras entre discurso crítico e ficcional, entre a linguagem filosófica e literária.

\section{Nietzsche - Pforta}

Em suas anotações para as férias de verão de 1863, Nietzsche planeja elaborar uma análise da Canção dos Nibelungos, contrastando-a com a Ilíada de Homero e dirigindo o olhar para uma determinada perspectiva: "o ponto de vista estético da canção na representação do terrível e do belo" (BAWII, p.221). O jovem destaca a beleza como o tema comum aos dois poemas, ressaltando o paralelo entre as principais personagens, Kriemhild e Helena, descritas como "as mais belas mulheres". Se na epopeia homérica a beleza de Helena está no centro dos acontecimentos, na saga germânica Siegfried decide ir à corte dos Burgúndios, onde vive Kriemhild, sob o fascínio dos relatos que escutou de sua indescritível beleza. Nietzsche inicia seus comentários com as estrofes que abrem o poema, indicando "a crença nos sonhos" e as "singulares alegorias" (Ibid, p.221) como elementos que desempenham um importante papel na narrativa. Logo no início, Kriemhild relata a sua mãe, Ute, um sonho terrível: o falcão forte, belo e selvagem criado pela jovem é, diante dela, estraçalhado por duas águias. O falcão é interpretado por Ute como um homem nobre, Siegfried, que se casará no curso da trama com Kriemhild. Já as águias, aparentadas ao falcão, como sugerem as imagens, aludem ao rei Günter, pai de Kriemhild, e a seu vassalo Hagen, personagens que terão papel decisivo no destino trágico de Siegfried. Com essas imagens e, como observa Nietzsche, com a "simplicidade e economia" das alegorias (BAWII, p. 248), o conjunto da trama é logo de início apresentado ao ouvinte. O sonho, com a força de suas imagens, é também uma forma de expressar os afetos 
da personagem, ressaltados por Nietzsche a partir da citação da seguinte passagem: “dor maior nessa terra não poderia acontecer a ela". ${ }^{18}$ Assim, os dois elementos mencionados pelo jovem, o sonho e as alegorias, não apenas configuram o horizonte da trama, mas a ela imprimem uma tonalidade afetiva, anunciando seu caráter trágico.

Mas sendo o ponto de vista estético, como vimos, o núcleo da investigação, Nietzsche busca, ao lado do terrível, o modo como o belo é representado na canção. A partir do paralelo com a Ilíada, o jovem sugere um segundo aspecto em comum entre os dois poemas: além da beleza constituir em ambos o tema, raras são as passagens nas quais ela é descrita. A esse respeito observa que não há, no primeiro episódio, "nenhum vestígio de descrição (Schilderung) da beleza", traço marcante da personagem, o que aproxima o poema da epopeia de Homero, já que tudo aquilo que o poeta grego "não podia descrever em seus elementos, nos dava a conhecer em seus efeitos" (BAWII, p. 227). Nietzsche constata que a beleza não é descrita de forma direta no poema, mas de forma indireta, por alegorias e comparações, sendo este o principal meio empregado pelo poeta na construção da narrativa. Assim, a indagação, colocada no início, sobre o modo como a Canção representa o belo, é por ele respondida com a seguinte observação: "Por meio da impressão que suscita no outro, por meio de comparações" (BAWII, p. 226).

A partir de uma seleção de passagens do terceiro episódio, o jovem analisa cada um dos elementos acima a fim de elucidar o emprego específico de formas poéticas. Nietzsche cita um trecho do terceiro episódio, no qual é narrado o momento em que o herói vê a jovem pela primeira vez, para evidenciar o "notável efeito" produzido

\footnotetext{
18 Nietzsche cita o poema diretamente do alemão arcaico a partir da edição crítica Der Nibelunge Not mit der Klage, organizada por Karl Lachmann (Berlin, 1826). Para a tradução das citações, tomei como base a obra de Karl Simrock (Das Nibelungenlied. Stuttgart: 1868), cuja tradução do alemão arcaico para o moderno fazia parte do acervo da biblioteca de Pforta e era citado por Nietzsche em suas leituras das sagas nórdicas (BAW I, p.245). Utilizei, ainda, a tradução de Siegfried Grosse (Das Nibelungenlied. Mittelhochdeutsch/Neuhochdeutsch. organizada por Ursula Schulze. Stuttgart: Reclam, 2010).
}

164 | Cad. Nietzsche, Guarulhos/Porto Seguro, v.42, n.2, p. 147-174, maio/agosto, 2021. 
Da estética romântica à arte do estilo: conexões do jovem Nietzsche...

pelo texto: "Eis que surge a jovem, como a aurora que desponta entre turvas nuvens, e se dissipam no coração de Siegfried, aflições que há muito carregava" (BAWII, p. 229). Assim como a aparição da personagem é comparada à aurora, que irrompe num céu cheio de nuvens, Siegfried fortalece seu ânimo diante da luminosa visão e se dissipam suas preocupações. No lugar de descrever um acontecimento específico, desdobrando-o em seus elementos, o poeta introduz um jogo de imagens, indicando por esse jogo e sua polifonia o modo como o acontecimento irradia, os efeitos por ele produzido. $\mathrm{O}$ acontecimento não é, portanto, diretamente descrito, mas sugerido por um jogo de imagens. Algo semelhante ocorre com as comparações empregadas pelo poeta para expressar a beleza da personagem. Nietzsche reúne vários trechos, nos quais a beleza é indiretamente descrita nas "pedras preciosas que brilham no vestido", no "tom cintilante da pele", na "lua cheia que, pairando diante das estrelas, brilha luminosa entre as nuvens" (BAWII, p. 230). Para o jovem a passagem que melhor expressa o uso do efeito como forma de sugerir o acontecimento é aquela que narra as impressões de Siegfried diante da beleza da personagem, o que o leva a observar que "a mais forte impressão", suscitada pelo poema, "é aquela apresentada em Siegfried". Aqui o poeta indica os afetos do herói pela mudança das cores de seu rosto e nos leva a imaginar a cena comparando-a com a tela de uma pintura: "Com esses pensamentos, ele empalidecia e de novo ruborizava". "Ali permanecia tão encantadoramente, como se em uma tela um mestre de arte o tivesse pintado" (BAWII, p. 230). Os trechos citados por Nietzsche visam elucidar os recursos artísticos empregados para expressar a beleza, consistindo tais recursos não apenas em "comparações", mas também na vivacidade com que o poeta narra a "impressão" que a visão do belo suscita nos personagens. Assim, a indagação acerca do modo como o poema representa o belo conduz a uma análise do meio indireto de expressão contido nas comparações, 
Cavalcanti, A. H.

depreendendo-se de tal análise a importância das alegorias e dos efeitos poéticos como recursos literários.

Nietzsche inicia sua investigação, como vimos, destacando a beleza como motivo comum à Ilíada e à Canção dos Nibelungos. Pouco a pouco, no entanto, deixa esse aspecto em segundo plano e passa a abordar a beleza como forma de expressão, explorando os meios empregados pelo poeta, comentando e procurando discernir no que consistem tais recursos expressivos. Ele passa a se ocupar, portanto, não com o tema da beleza, que nos remete a um conteúdo que pode ser descrito, mas com o modo como a beleza é apresentada, o que implica as lacunas de uma narrativa que jamais apreende o belo, deixando-o antes deslizar entre comparações, nas quais uma coisa é dita por outra, uma coisa remete a outra, numa amplificação do campo semântico. Exemplar nesse sentido são os termos empregados pelo jovem, que trabalha uma constante contraposição entre o termo "descrição" (Schilderung), que remete a algo determinável, cujos componentes podem ser evidenciados, e o termo "efeito" (Wirkung), que remete a um modo indireto de expressão, ao emprego de comparações e alegorias, e às diferentes impressões por ele suscitadas.

Na sequência das observações estéticas sobre a Canção dos Nibelungos, a contraposição entre "descrição e efeito" é retomada a partir da indagação sobre os meios de expressão da emoção no poema. Buscando indícios de como o poeta expressa a "sensação da alma dos heróis épicos", o modo como apresenta os processos internos, Nietzsche observa que isso se dá por "alegorias (Gleichnisse) para o movimento da alma e do corpo", "por meio do efeito sobre outras pessoas" e "por meio de indicações do próprio poeta", acrescentando: "em nenhuma parte descrição (Schilderung) de sensações da alma, mas sempre somente os efeitos (Wirkungen)" (BAWII, p. 247). As alegorias operam em um modo indireto de expressão que, no lugar de tornar inteligível um conteúdo, evidenciá-lo por sua descrição, comunica-se pelo jogo de efeitos que produz, seja o efeito sobre 
Da estética romântica à arte do estilo: conexões do jovem Nietzsche...

os personagens do poema, seja o efeito sobre o leitor. Assim, se o jovem Nietzsche não encontra no poema, como vimos, uma descrição direta da beleza, é no sentido de que tal beleza é apreensível sempre indiretamente, no impacto que produz nos personagens do poema, em seu espanto, em sua surpresa, e esse impacto por sua vez suscita impressões no leitor, desencadeando um modo de compreensão conduzido pelas imagens.

Grande parte das anotações sobre a Canção visa analisar trechos relativos às "belas imagens", às "maravilhosas comparações" ou aos "notáveis efeitos", ${ }^{19}$ o que remete aos recursos empregados pelo poeta na representação do belo e à especificidade de sua forma de expressão. Além disso, com o uso dos termos "descrição" e "efeito", o jovem mostra-se atento aos contrastes entre determinação e indeterminação da forma, aproximando-se dos estudos de seu professor de alemão sobre a estética do primeiro romantismo, nos quais eram abordadas questões relativas aos meios de expressão na poesia e na prosa, suas fronteiras e conexões. Vale ressaltar, como anteriormente observado, que Nietzsche estuda com Koberstein justamente no período de redação do último volume do Grundriss, no qual os desdobramentos da investigação do movimento romântico sobre a forma de expressão na poesia são abordados com riqueza de detalhes. Tornam-se visíveis aqui duas movimentações que coincidem em certos aspectos: enquanto Koberstein concentra cada vez mais esforços em elucidar as conexões entre crítica e criação poética, Nietzsche dirige seu interesse ao ponto de vista estético e este, por sua vez, se traduz em um estudo dos aspectos formais e expressivos da literatura antiga. $\mathrm{O}$ estudante investiga os meios empregados pelo poeta para apresentar processos internos, especialmente o uso de alegorias nas antigas canções, orientando suas indagações em torno da questão da forma de expressão.

19 Cf. BAWII, respectivamente p.241, 237, 229. 
Cavalcanti, A. H.

\section{Nietzsche - Leipzig}

Três anos mais tarde, em 1866, durante seu doutorado de filologia clássica na Universidade de Leipzig, Nietzsche participa cada vez mais estreitamente dos círculos filológicos, integrando associações e grupos de estudo, além de estabelecer com Ritschl, seu orientador, uma relação de forte admiração e cooperação. Com o incentivo de seu orientador, que desde o início impressiona-se com a "incomparável combinação e rigor metódico" ${ }^{20}$ de seus trabalhos, 0 jovem prepara a publicação de seu primeiro artigo, cujo tema consiste na história das compilações das obras de Teógnis. Ao mesmo tempo, Nietzsche fortalece os vínculos com a filosofia de Schopenhauer, cuja obra conhecera no ano anterior, formando grupos regulares de leitura com seus amigos e elaborando suas próprias reflexões. Nas cartas do período, percebe-se que o jovem vivencia esses dois campos de interesse como mundo separados, a pesquisa no campo da filologia, no qual conta com o dedicado apoio de Ritschl, e o universo da filosofia de Schopenhauer, cujo fascínio compartilha com seus amigos. ${ }^{21}$ Com todo o entusiasmo e admiração que o ligam a seu orientador, Nietzsche não deixa de perceber seus limites, observando que ele "valoriza em excesso sua disciplina", demarcando rigidamente a fronteiras entre os saberes, e "não vê com bons olhos que filólogos se ocupem com filosofia" (Apud JANZ, 1984, p. 156).

O relato de uma espécie de cisão entre os dois campos encontra-se nas cartas escritas ao longo do período de redação do artigo sobre Teógnis, período, portanto, de intensa dedicação à filologia. Em carta a Gersdorff (6 de abril de 1866, KSB 2.121), referindo-se ao trabalho crítico com os manuscritos, Nietzsche

20 Ver JANZ, C. Nietzsche. Biographie. Vol. 1. Paris: Gallimard, 1984, p.155.

21 Em carta a seu tio Oehler, de 15 de janeiro de 1866 (KSB 2.107), o jovem comenta com entusiasmo a sua relação com Ritschl, enquanto em carta à mãe, de 31 de janeiro (KSB 2. 109), referindo-se a Schopenhauer, afirma que "este filósofo ocupa uma parte muita significativa de minhas reflexões e de meu trabalho".

168 | Cad. Nietzsche, Guarulhos/Porto Seguro, v.42, n.2, p. 147-174, maio/agosto, 2021. 
Da estética romântica à arte do estilo: conexões do jovem Nietzsche...

lamenta ter de impor a si por meio da atividade filológica a "máscara de uma erudição" que ele não possui e que o "afasta de si mesmo (e de Schopenhauer)". Alguns meses depois, enquanto elabora a versão final de seu artigo, o jovem declara ao amigo: "Jamais escrevi com tanto desprazer; por fim debitei a matéria do modo mais uniforme" (Carta a Gersdorff de fim de agosto de 1866, KSB 2.157). Curioso em tais comentários é que a filologia é associada não apenas a um tipo mascarado de erudição, marcado por excesso de citações, mas a uma forma uniforme, em tudo oposta à atividade prazerosa de moldar, dar forma, imprimir contornos a uma matéria. É justamente esse prazer da forma que começa a se insinuar com crescente clareza na experiência de escrita do jovem Nietzsche. Em novembro de 1866, Ritschl propõe a seu orientando um novo tema de pesquisa, "As fontes de Diógenes Laércio", que lhe abre a possibilidade de estreitar contato com a filosofia grega. A redação desse trabalho, ao qual Nietzsche se entrega com entusiasmo, será marcada pela busca de uma "forma artística" (KSB 2.205), cujos passos serão descritos com riqueza de detalhes em suas cartas.

Em carta a Deussen, o jovem faz um balanço de sua experiência com o primeiro artigo e descreve a dificuldade que encontra para dar a sua escrita um estilo. Para isso é preciso aprender a dominar uma certa tendência ao supérfluo, a um excesso de clareza e de evidência que sobrecarrega o texto e impede um trabalho criativo com a forma:

Meu esforço agora é não dar a ver de modo tão evidente a estrutura lógica, como foi o caso de meu estudo sobre Teógnis. E isso não é fácil. Gostaria de dar a esse tipo de trabalho uma forma artística. Por isso, evito sempre que posso a erudição desnecessária, embora isso me seja custoso, pois é preciso suprimir muito de supérfluo que costuma nos agradar. Uma rigorosa exposição das provas, em uma apresentação leve e aprazível, se possível sem aquela seriedade morosa e aquela erudição abarrotada de citações, tal é o meu desejo (Carta a Deussen de 04 de agosto de 1866, KSB 2. 205-206). 
O desejo de uma arte estilística corresponde ao desejo de não dar a ver algo de modo muito evidente, imprimindo ao texto o trabalho da forma, moldando-o de modo aprazível, em uma composição na qual argumento e linguagem se configurem mutuamente. Nesse sentido, forjar um estilo requer um esforço sobre si próprio, o constante exercício de impor limites ao excesso de comentários eruditos, acompanhados de inumeráveis citações, combinando rigor e leveza em uma composição da forma.

Se o ginasiano concentrara seu interesse na especificidade dos meios de expressão na literatura, o estudante universitário retoma e renova a reflexão sobre a forma, já que agora ele a dirige a um texto acadêmico, que envolve a precisão da linguagem e a construção de argumentos. Semelhante ao estudo da poesia, que priorizava o modo indireto de expressão, o desejo de dar forma artística ao trabalho filológico se traduz no esforço de despojar o texto de um excesso de evidência, o que implica que o argumento, com sua cadeia de provas, deve ser combinado e moldado na riqueza expressiva da linguagem.

Esse tema é retomado, alguns dias depois, em uma carta a Gersdorff, na qual Nietzsche compara o esforço para aprimorar sua escrita com o paciente trabalho de entalhe ou esculpe, observando que Lessing, Lichtenberg e Schopenhauer foram unânimes em afirmar que o bom estilo é adquirido, exige dedicação. O trabalho artístico da forma é, em seguida, associado a uma arte do improviso musical:

De súbito me dei conta: permaneci tempo demasiado em estado de inocência estilística. [...] Espero realmente nunca mais escrever dessa maneira seca e morta, presa a um espartilho lógico, que empreguei em meu trabalho sobre Teógnis: nesse berço não se pode embalar nenhuma graça! [...] Que espíritos animados se soltem de novo em meu estilo, preciso nele aprender a tocar como no piano, não apenas peças conhecidas, mas livres improvisos, muito livres, embora sempre lógicos e belos (Carta a Gersdorff de 6 de abril de 1867, KSB 2. 209). 
Da estética romântica à arte do estilo: conexões do jovem Nietzsche...

A busca de criar para si um estilo é formulada aqui como uma espécie de despertar, os olhos, que agora se abrem para a forma de expressão, vislumbram para o estudo filológico um modo de exposição que não se deixa capturar pela determinação de polos opostos, como aqueles que delimitam arte e ciência, mas que devem se exercitar no deslocamento de suas fronteiras. A forma convencional do tratado científico, objetiva e sem fantasia, deve incorporar os elementos figurativo e plástico da linguagem, conferindo à prosa graça e movimento. $\mathrm{O}$ jovem compara o aprendizado da arte estilística com o exercício do improviso musical, no qual quanto mais livre o movimento das variações, tanto mais lógica e bela se tornam. Assim, argumento e expressividade, entendimento e imaginação aliamse no estilo, rompendo com formas convencionais da linguagem, introduzindo na escrita livres variações.

Em uma carta a Mushake, do mesmo mês, na qual refere-se aos anos de estudo em Pforta, Nietzsche renova seu comentário de que o bom estilo, para se converter em arte, requer um lento e paciente exercício:

Deparei-me com um obstáculo dificilmente perceptível antes; simplesmente não tenho estilo em alemão, embora tenha o vivo desejo de adquirir um. Como me propus a elaborar, cuidadosamente, meu estudo sobre Laércio em alemão, antes de fazer seu esboço em latim, fui levado a me aprofundar em questões estilísticas. Sabe-se que, como ginasiano, não se escreve com estilo; como estudante não se tem ocasião para o exercício; o que se escreve são cartas, formas de expansão subjetiva sem nenhuma pretensão a uma forma artística. Mas termina por vir o tempo em que a tabula rasa de nossa arte estilística emerge à consciência. Isso acontece comigo agora e daí o fato de eu só poder trabalhar muito lentamente (Carta a Mushake, 20 de abril 1867, KSB 2. 214).

Aqui, mais uma vez, a busca de estilo articula exercício e arte, trabalho e forma. Mas nessa carta se desenha, ainda, um contraste entre o ginasiano, que escreve sobretudo cartas, e o universitário, que 
se dedica a seus primeiros artigos científicos, nos quais se confronta não apenas com questões específicas de sua disciplina, mas com a arte de apresentá-las. Nos anos de doutorado, como vimos, Nietzsche expõe sua crítica à rígida demarcação entre os saberes, que mantinha filosofia e filologia como dois campos separados, impossibilitando o exercício de variação de perspectivas no conhecimento. Curiosamente, a reflexão sobre o estilo surge no mesmo período e contribui para ampliar a visão crítica acerca da fronteira entre os saberes, já que introduz a forma, a riqueza expressiva da linguagem, como algo que diz respeito ao conhecimento, que constitui o meio pelo qual ele se dá, configurando um campo no qual não há oposição, mas conexão entre arte e ciência. Assim, a indagação do jovem dirige-se não apenas às fronteiras entre formas de conhecimento, como filologia e filosofia, mas às fronteiras entre conhecimento e arte, tema com o qual se ocuparam intensamente os pensadores românticos, que transitavam entre múltiplos campos, filosofia, poesia, crítica, tradução, experimentando a desconstrução de suas fronteiras.

Aqui se delineia pontos significativos de contato entre o horizonte do primeiro romantismo alemão, vivamente exposto por Koberstein, especialmente no que diz respeito à escrita poéticofilosófica, e os anos de formação de Nietzsche, que incorpora de modo cada vez mais produtivo a questão da forma de expressão a sua atividade de reflexão e de escrita. 
Da estética romântica à arte do estilo: conexões do jovem Nietzsche...

\title{
From romantic aesthetics to the art of style: young Nietzsche's connections with August Koberstein
}

\begin{abstract}
The aim of this article is to investigate the increasingly prominent place that the question of the form of expression takes in Nietzsche's writings between the end of his school studies and his first years of university studies. I intend to elucidate the analysis developed by Koberstein in his work Outline of the History of German National Literature on the issue of the form of expression in the romantic movement, to then show how Nietzsche's growing interest in the use of expressive resources in the old poems unfolded during the university period in his search for a stylistic art that would be understood as a link between art and science.

Keywords: Nietzsche, Koberstein, style, literature, philosophy, romantic aesthetics.
\end{abstract}

\section{Referências}

BEHLER, Ernst. Le premier romantisme allemand. Trad. E. Décultot e C. Helmreich. Paris: PUF, 1992.

BOHLEY, Reiner. Über die Landesschule zur Pforte: Materialien aus der Schulzeit Nietzsches. In: Nietzsche-Studien 5, 1976, p. 298-320.

CAVALCANTI, Anna Hartmann. Antigas sagas e canções; o despertar de Nietzsche para a estética romântica em Pforta. In: Estudos Nietzsche, 2019, vol. 10, n.2, p, 102-118.

CAVALCANTI, Anna Hartmann. Poesia e linguagem na primeira recepção de Nietzsche dos escritos de August Wilhelm Schlegel. In: Cadernos Nietzsche, 2017, vol.38, n.2, p.121-148.

Das Nibelungenlied. Mittelhochdeutsch/Neuhochdeutsch. Nach der Handschrift B herausgegeben von Ursula Schulze ins Neuhochdeutsche übersetzt und kommentiert von Siegfried Grosse. Stuttgart: Reclam, 2010. 
Cavalcanti, A. H.

Das Nibelungenlied. Trad. Karl Simrock. Stuttgart: 1868.

FIGL, Johann. Os primeiros contatos de Nietzsche com o pensamento asiático. Tradução de Fernando de Moraes Barros. Cadernos Nietzsche 15, 2003, p. 83-103.

HEUMANN, Hans. Schulpforta: Tradition und Wandel einer Eliteschule. Erfurt: Verlagshaus Thüringen, 1994.

HEYER, Fritz. Aus der Geschichte der Landesschule zur Pforte. Darmstadt; Leipzig: Buske, 1943.

HÖDL, Hans Gerald. Schriften der Schulzeit (1854-1864) in: OTTMANN, H. Nietzsche Handbuch, Metzler: 2000.

JANZ, Curt Paul. Nietzsche. Biographie. Vol. 1. Paris: Gallimard, 1984.

KOBERSTEIN, August. Grundriss zur Geschichte der deutschen Nationalliteratur. $4^{\text {a }}$ edição revisada e ampliada, Leipzig: Vogel, volume 1, 1847; volume 2, 1856; volume 3, 1866.

NIETZSCHE, Friedrich. Historisch-kritische Gesamtausgabe (BAW). org. por H.J.Mette/K.Schlechta. Vol. 2, München: 1994.

NIETZSCHE, Friedrich. Sämtliche Briefe. Kritische Studienausgabe in 8 Bänden (KSB) hrsg. v. G. Colli u. M. Montinari. München: Walter de Gruyter, 1986.

NIETZSCHE, Friedrich. Werke. Kritische Gesamtausgabe. Nachgelassene Aufzeichnungen (Herbst 1858 - Herbst 1862). Figl, J. e Hödl, H. G. (org), Berlin/New York: Walter de Gruyter, v. I/2, 2000.

NIETZSCHE, Friedrich. Werke. Kritische Gesamtausgabe. Nachgelassene Aufzeichnungen (Herbst 1862 - Sommer 1864). Figl, J. e Hödl, H. G. (org), Berlin/New York: Walter de Gruyter, v. I/3, 2006.

TODOROV, Tzvetan. Teorias do símbolo. Campinas: Papirus, 1996.

Enviado: 04/04/2021

Aceito:04/06/2021

174 | Cad. Nietzsche, Guarulhos/Porto Seguro, v.42, n.2, p. 147-174, maio/agosto, 2021. 